\title{
Medical leaders propose appointing wellness officers to address physician burnout
}

\author{
— Cite as: CMAJ 2019 March 4;191:E267. doi: 10.1503/cmaj.109-5719
}

Posted on cmajnews.com on Feb. 12, 2019.

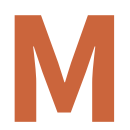
edical leaders in the United States are urging health organizations to appoint executivelevel wellness officers to lead reforms to reduce physician burnout.

One recent report from Harvard University, the Massachusetts Medical Society, and the Massachusetts Health and Hospital Association warned that care is being compromised by "critical levels" of burnout among doctors. According to coauthor Dr. Alain Chaoui, "we need our health care institutions to recognize burnout at the highest level and to take active steps to survey physicians for burnout and then identify and implement solutions."

The report calls on major health organizations to hire chief wellness officers to lead these efforts. According to the authors, "successful interventions require senior, visible leadership equipped with a mandate and authority to work systemically across departments, portfolios and other silos."

Several health organizations, including Stanford Medicine and Kaiser Permanente, have appointed chief wellness officers in the past few years. In Health Affairs, leaders from Stanford University, the Icahn School of Medicine at Mount Sinai and the Johns Hopkins Health System argued that executive-level leadership is vital to provide legitimacy and financial support for wellness efforts.

Hiring a chief wellness officer also makes good business sense, they wrote. Research links burnout to reduced productivity and quality of care, as well as increased turnover and medical errors. One study found that for every dollar spent on wellness, hospitals see a \$3-\$6 return on investment. Many organizations already have various wellness efforts underway. However, according to the

authors of the Health Affairs paper, "unless there is a concerted focus on clinician wellbeing from the executive level, dramatic changes will not occur."

Some front-line physicians are skeptical of this claim. Recent comments on a Medscape article described the role as "another empty suit job." Several of those who posted argued that increases to administrative control and oversight are contributing to burnout. Others ques-

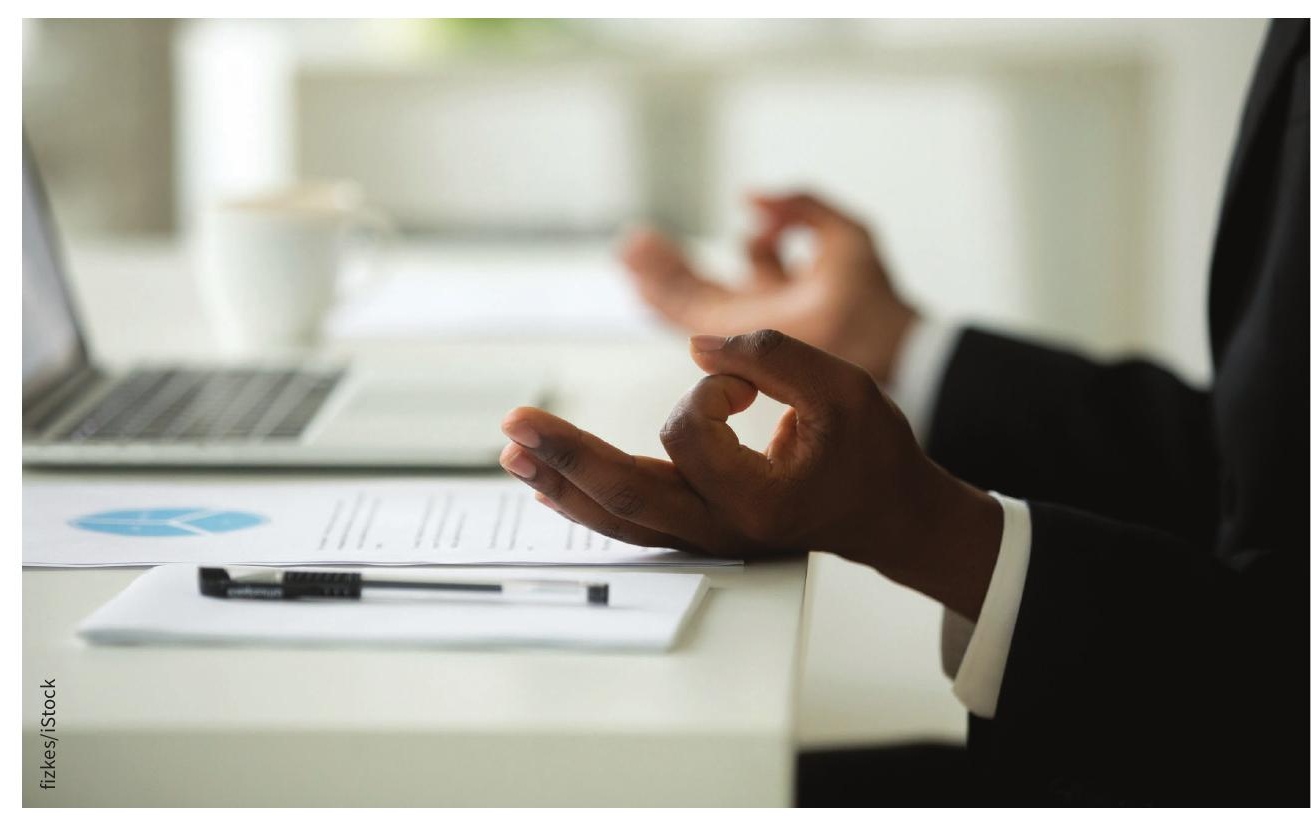

Recent reports call on health organizations to create a new executive role to combat physician burnout.

tioned how wellness officers would benefit the many physicians working outside of major organizations.

According to the authors of the Health Affairs paper, the benefits of hiring a chief wellness officer "may be difficult to observe in the short term." However, they cited the early success of a program overseen by a chief wellness officer at Ohio State University that was linked to improved well-being and reduced health care use among employees.

Part of the challenge is that health organizations have only recently recognized the role they play in physician burnout. "We just didn't appreciate the magnitude of the problem," said Dr. Caroline Gérin-Lajoie, recently appointed as the Canadian Medical Association's first vice-president of physician health and wellness. "Many initiatives were really geared to the individual phys- 